\title{
Multivisceral organ failure related to leptospirosis in pregnant patient
}

\author{
Sbai Hicham, Mellouki ihsane ${ }^{1}$, El Bouazzaoui Abderahim, Boukatta Brahim, Smail Labib, \\ Harrandou Mustapha, Khatouf Mohamed, Ibrahimi Adil ${ }^{1}$, Melhouf Abdelilah ${ }^{2}$, Kanjaa Nabil
}

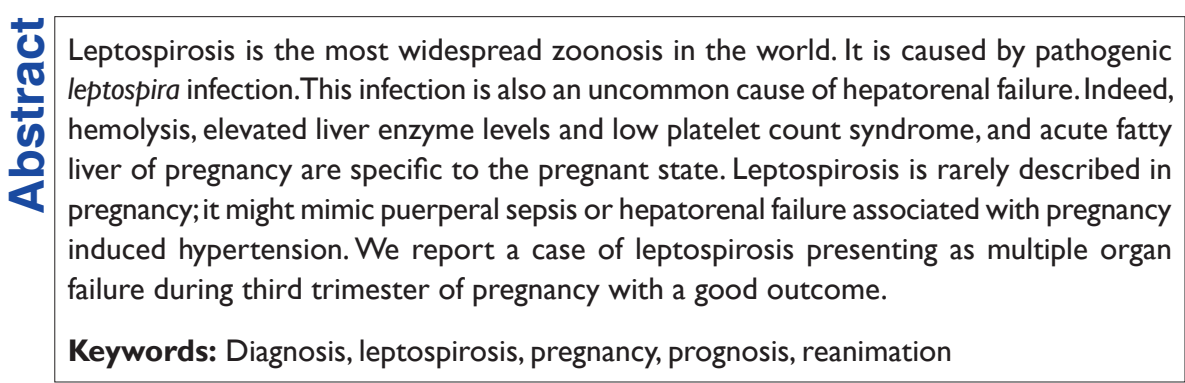

\section{Introduction}

Leptospirosis, an unusual spirochaetal infection, might occur at all ages and rarely on pregnant women. The diagnosis is based on urine and serological tests; the cerebrospinal fluid assessment is also performed. For the fetus, there are significant risks of transplacental infection and subsequent loss of viability.

\section{Case Report}

A 35-year-old multiparous woman in 36th week of gestation with no significant past history presented to emergency with a short history of 8 days of malaise, chills, myalgia, jaundice, abdominal pain, and asthenia. At admission, the clinical parameters were - heart rate $120 / \mathrm{min}$, blood pressure 105 / $66 \mathrm{mmHg}$, respiratory rate $17 / \mathrm{min}$, axillary temperature $38^{\circ} \mathrm{C}$, and oliguria of $500 \mathrm{ml}$ in last 24 hours. The patient was conscious but

From:

Department of Anaesthesia and Reanimation, University Hospital Hassan II of Fez, Morocco ${ }^{1}$ Department of Hepato-gastroenterology, University Hospital Hassan II of Fez, Morocco ${ }^{2}$ Department of Gynecology and Obstetrics, University Hospital Hassan II of Fez, Morocco

\section{Correspondence:}

Dr. Sbai Hicham, Service D'anesthésie Reanimation A4, Centre Hospitalier Hassan II, Route Sidi Harazem, Fez, Morocco.

E-mail: hichamsbai77@yahoo.fr

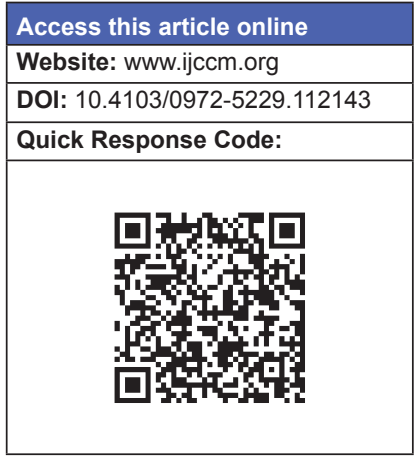

irritable with dark icterious conjunctive and bruises in all extremities.

Earlier during her pregnancy both systolic and diastolic arterial pressures were noted to be stable. There was no history of travel abroad, contact with animals, or fever. The obstetrical examination did not reveal any genital bleeding. The laboratory parameters were: hemoglobin $10 \mathrm{~g} / \mathrm{dL}$; leukocyte count: 15,2 × 10\% $/ \mathrm{L}$ including $75 \%$ neutrophils, platelets count: $40 \times 10^{9} / \mathrm{L}$; $C$ reactive protein $(C R P): 115 \mathrm{mg} / \mathrm{L}$, glucose: $0,92 \mathrm{~g} / \mathrm{L}$, creatinine: $18 \mathrm{mg} / \mathrm{L}$ and urea: $1.05 \mathrm{~g} / \mathrm{L}, \mathrm{AST}: 165 \mathrm{U} / \mathrm{L}$, ALT: $145 \mathrm{U} / \mathrm{L}$, bilirubin total: $7 \mathrm{mg} / \mathrm{dl}$, conjugated bilirubin: $5,8 \mathrm{mg} / \mathrm{dl}$. A moderate coagulopathy was found (PT 45\%, ACT 220 seconds, D-dimer $600 \mathrm{ng} / \mathrm{ml}$, fibrinogen 1,5 g/L), CPK: $355 \mathrm{U} / \mathrm{L}$, troponin Ic: 0.4., Blood and urine cultures were sterile, and the serology tests for hepatitis A, B, C, cytomegalovirus, and HIV were all negative. Leptospira IgM antibodies by enzymelinked immunosorbent assay were positive at $1 / 300$ dilution. The electrocardiogram revealed negative $\mathrm{T}$ waves in DII, DIII, and AVF. Ultrasound showed a single live pregnancy with oligohydramnios; Kidneys, spleen, and liver were normal and without any dilatation of the biliary canaliculi. The fetal cardiotocography was reactive. The interview of the family revealed that the patient had visited a public bath 15 days earlier. The 
initial management in the intensive care unit consisted of intravenous Penicillin G at 4000000 UI four times daily, hydration with crystalloid solutions, oxygenation by facemask. 10 hours after admission, she became severely icteric and developed severe respiratory distress with crackles on pulmonary auscultation requiring intubation and mechanical ventilation. An emergency cesarean section was performed. A healthy female weighing $2.9 \mathrm{~kg}$ was delivered with an Apgar of 6 and 8 respectively at $1 \mathrm{~min}$ and $2 \mathrm{~min}$ after delivery. Postoperatively, X-ray chest showed bilateral diffuse opacities; blood gases showed $\mathrm{PaO} 2 / \mathrm{FiO} 2<200$ and transthoracic echocardiography showed absence of increased left filling pressures fulfilling the American-European criteria for acute respiratory distress syndrome (ARDS). PAOP was not measured in the absence of Swan Ganz.

The post delivery treatment included mechanical ventilation with intravenous sedation, central venous pressure monitoring, restriction of fluid infusion and antibiotics (penicillin G). 4 days after delivery, the laboratory tests showed: hemoglobin $9.8 \mathrm{~g} / \mathrm{dL}$, leukocytes: $11 \times 10^{9} / \mathrm{L}, \mathrm{CRP}: 52 \mathrm{mg} / \mathrm{L}$, platelet: $106 \times$ 10\% $\mathrm{L}$, PT: t $60 \%$, fibrinogen: $3.5 \mathrm{~g} / \mathrm{l}$, urea: $0.55 \mathrm{~g} / \mathrm{L}$, creatinine: $11 \mathrm{mg} / \mathrm{L}, \mathrm{AST}: 60 \mathrm{U} / \mathrm{L}, \mathrm{ALT}: 52 \mathrm{U} / \mathrm{L}$, troponin Ic: 0,08 . Five days later, the patient's neurological and respiratory status improved, and 1 week later, she was discharged discharged from the ICU with antibiotics continued for 12 days. At follow up after 1 month of discharge the blood and urine were negative for leptospira and the neonate showed no signs of active infection.

\section{Discussion}

Leptospirosis is the most widespread zoonosis in the world, ${ }^{[1,2]}$ caused by all leptospiras regardless of specific serotype. It is particularly prevalent in tropical countries where environmental and socioeconomic conditions for its transmission are favorable. Rodents, especially rats, are the reservoir, and humans are not commonly infected. Human infections can occur either by direct contact with urine or tissue of an infected animal or indirectly through contaminated water, soil, or vegetation. ${ }^{[3,4]}$ More than $90 \%$ of symptomatic people have mild disease: fever, abdominal pain, chills, nausea, vomiting, headache, and myalgia. Conjunctival suffusion is very common and can be a useful clinical sign. Hepatorenal failure, pulmonary hemorrhage, myocarditis, rhabdomyolysis, and altered consciousness are the major manifestations. Thrombocytopenia indicates severe disease. A transaminase concentration is normal to moderate even in patients with severe jaundice, which differentiates it from viral hepatitis. A definite diagnosis is made on either isolation of the organism from the patient's urine, blood, or cerebrospinal fluid, or by serologic specific test (Microaggulitnation test). ${ }^{[2,5]}$ Leptospirosis is rare in pregnancy. There is little data regarding its effect on the pregnant woman and her fetus. ${ }^{[4,6]}$ In the third trimester of gestation, abdominal pain associated with jaundice and severe coagulation abnormalities is usually related to HELLP syndrome or AFLP. Both disorders show similar clinical and laboratory abnormalities, and diagnosis may be difficult. Gaspari et al. report a case of leptospirosis without fever during the late stage of pregnancy, mimicking the clinical pattern of HELLP syndrome or AFLP. ${ }^{[4]}$

This patient presented with classical features of severe leptospirosis: myocarditis, acute kidney injury, coagulopathy, acute respiratory distress syndrome, and liver dysfunction.

The frequency of leptospirosis in our context, history of poor hygienic condition, leukocytosis with neutrophilia, significant increase in bilirubin (predominantly conjugated) out of proportion to hepatic transaminases, and the chronological evolution were all suggestive of leptospirosis.

Urgent cesarean section was indicated to save the mother and fetus. Leptospirosis can be transmitted transplacentally. ${ }^{[7,8]}$ Variable perinatal outcomes are possible including intrauterine fetal death, abortion, healthy newborn or newborn showing signs of active infection. Gainder et al. present a case in a pregnant patient who presented with fever, jaundice, coagulopathy, and intrauterine fetal demise. ${ }^{[9]}$ Baytur et al. reported a case of preterm delivery with fetal loss. ${ }^{[6]}$ In our case, the baby did not develop signs of infection. Treatment with antibiotics remains the primary intervention. Penicillin G, streptomycin, choramphenicoal, and erythromycin have been effective in treating these patients. ${ }^{[3,7]}$ Intensive care management is often necessary in severe cases. Fluid and electrolyte balance needs to be monitored while patients with renal involvement can may require dialysis. Mechanical ventilation is indicated in cases of respiratory distress. A few cases in the literature have reported that plasma exchange, corticosteroids, and intravenous immunoglobulin may be beneficial in selected patients in whom conventional therapy does not elicit a response. ${ }^{[5,10]}$ The presence of oliguria, hyperkalemia, pulmonary rales, or hypotension on admission in patients with leptospirosis indicated high risk of death. ${ }^{[5,11]}$ The mortality rate in severe leptospirosis has been described as ranging from 5-40\%. ${ }^{[4,11]}$ 


\section{Conclusion}

We report a case with a clinical profile of leptospirosis that might mimic pregnancy-related liver dysfunction. Leptospirosis should be considered as a differential diagnosis in any pregnant woman with hepatrenal disease.

\section{References}

1. Chawla V, Trivedi TH, Yeolekar ME. Epidemic of leptospirosis. J Assoc Physicians India 2004;52:1010-1.

2. Bharti AR, Nally JE, Ricaldi JN, Matthias MA, Diaz MM, Lovett MA, et al. Leptospirosis: A zoonotic disease of global importance. Lancet Infect Dis 2003;3:757-71.

3. Jaureguiberry S, Roussel M, Brinchault-Rabin G, Gacouin A, LeMeur A, Arvieux C, et al. Clinical presentation of leptospirosis: A retrospective study of 34 patients. Clin Microbiol Infect 2005;11:391-4.

4. Gaspari R, Annetta MG, Cavaliere F, Pallavicini F, Proietti R, Grillo R, et al. Unusual presentation of leptospirosis in the late stage of pregnancy. Minerva Anestesiol 2007;73:429-32.

5. Vieira SR, Brauner JS. Leptospirosis as a cause of acute respiratory failure: Clinical features and outcome in 35 critical care patients. Braz
J Infect Dis 2002;6:135-9.

6. Baytur YB, Lacin S, Koyuncu FM, Cabuk M, Ceylan C, Kandiloglu AR. Weil's syndrome in pregnancy. Eur J Obstet Gynecol Reprod Biol 2005;119:132-3.

7. Ch'ng CL, Morgan M, Hainsworth I, Kingham JG. Prospective study of liver dysfunction in pregnancy in southwest Wales. Gut 2002;51:876-80.

8. Pereira SP, O'Donohue J, Wendon J, Williams R. Maternal and perinatal outcome in severe pregnancy-related liver disease. Hepatology 1997;26:1258-62.

9. Gainder S, Singla R, Dhaliwal L, Suri V. Leptospirosis as a cause of intrauterine fetal demise: Short report of rare presentation. Arch Gynecol Obstet 2010;281:1061-3.

10. Siriwanij T, Suttinont C, Tantawichien T, Chusil S, Kanjanabuch T, Sitprija V. Haemodynamics in leptospirosis: Effects of plasmapheresis and continuous venovenous haemofiltration. Nephrology (Carlton) 2005; $10: 1-6$.

11. Panaphut T, Domrongkitchaiporn S, Thinkamrop B. Prognostic factors of death in leptospirosis: A prospective cohort study in Khon Kaen, Thaïland. Int J Infect Dis 2002;6:52-9.

How to cite this article: Hicham S, ihsane M, Abderahim E, Brahim B, Labib S, Mustapha $\mathrm{H}$, et al. Multivisceral organ failure related to leptospirosis in pregnant patient. Indian J Crit Care Med 2013;17:43-5.

Source of Support: Nil, Conflict of Interest: None declared.

\section{New features on the journal's website}

Optimized content for mobile and hand-held devices

HTML pages have been optimized for mobile and other hand-held devices (such as iPad, Kindle, iPod) for faster browsing speed.

Click on [Mobile Full text] from Table of Contents page.

This is simple HTML version for faster download on mobiles (if viewed on desktop, it will be automatically redirected to full HTML version)

\section{E-Pub for hand-held devices}

EPUB is an open e-book standard recommended by The International Digital Publishing Forum which is designed for reflowable content i.e. the text display can be optimized for a particular display device.

Click on [EPub] from Table of Contents page.

There are various e-Pub readers such as for Windows: Digital Editions, OS X: Calibre/Bookworm, iPhone/iPod Touch/iPad: Stanza, and Linux: Calibre/Bookworm.

\section{E-Book for desktop}

One can also see the entire issue as printed here in a 'flip book' version on desktops.

Links are available from Current Issue as well as Archives pages.

Click on $1 \mathrm{e}$ View as eBook 